\title{
The Clinical Features of Preschool Children With Speech and Language Disorder and the Role of Maternal Language
}

\author{
Hyeong Seop Kim, MD ${ }^{1}$, Heesuk Shin, $\mathrm{MD}^{1,2}$, Chul Ho Yoon, $\mathrm{MD}^{1,2}$, Eun Shin Lee, $\mathrm{MD}^{1,2}$, \\ Min-Kyun Oh, MD ${ }^{1,2}$, Se-Woong Chun, MD ${ }^{1}$, Seung-Kyu Lim, MD ${ }^{1}$, Hoi Sik Min, MD' , Hayoung Byun, MD \\ ${ }^{1}$ Department of Rehabilitation Medicine, Gyeongsang National University Hospital, Gyeongsang National University School of \\ Medicine, Jinju; \\ ${ }^{2}$ Institute of Health Science, Gyeongsang National University, Jinju, Korea
}

\begin{abstract}
Objective To retrospectively review the characteristics of preschool children with speech and language disorders to determine their clinical features and compares the average degrees of language delay based on hospital visit purposes, language developmental delay causes, and maternal language.

Methods One thousand one hundred two children (832 males, 270 females) with the chief complaint of language or speech problems who underwent language assessment for the first time were included. Their medical records, including demographic data, language environments, and family history of language problems and other developmental problems, were collected. Furthermore, the results of language and developmental assessments and hearing tests were collected.

Results Among the children enrolled in this study, $24 \%$ had parental problems and $9 \%$ were nurtured by their grandparents. The average degree of language delay did not differ regarding purposes of hospital visits. The average degree of language delay was greatest in children with autism spectrum disorders and least in children with mixed receptive-expressive language disorders. In children with mothers who do not speak Korean as their native language, social quotients in the social maturity scale were less than 70 .

Conclusion Language environment is an essential factor that may cause speech and language disorders. Moreover, maternal language seems to affect the social quotient of the social maturity scale.
\end{abstract}

Keywords Language development, Language development disorders, Language test, Child language

Received July 6, 2020; Revised August 19, 2020; Accepted September 23, 2020; Published online February 9, 2021

Corresponding author: Hayoung Byun

Department of Rehabilitation Medicine, Gyeongsang National University Hospital, Gyeongsang National University School of Medicine, 79 Gangnamro, Jinju 52727, Korea. Tel: +82-55-750-8256, Fax:+82-55-750-8255, E-mail: minusbyun@naver.com

ORCID: Hyeong Seop Kim (https://orcid.org/0000-0001-5022-6030); Heesuk Shin (https://orcid.org/0000-0003-4181-2825); Chul Ho Yoon (https:// orcid.org/0000-0003-4916-4180); Eun Shin Lee (https://orcid.org/0000-0002-7764-1522); Min-Kyun Oh (https://orcid.org/0000-0003-0258-6298); SeWoong Chun (https://orcid.org/0000-0002-6453-8649); Seung-Kyu Lim (https://orcid.org/0000-0002-6867-2896); Hoi Sik Min (https://orcid.org/00000002-0732-218X); Hayoung Byun (https://orcid.org/0000-0003-1426-6582).

(c) This is an open-access article distributed under the terms of the Creative Commons Attribution Non-Commercial License (http://creativecommons.org/ licenses/by-nc/4.0) which permits unrestricted noncommercial use, distribution, and reproduction in any medium, provided the original work is properly cited. Copyright () 2021 by Korean Academy of Rehabilitation Medicine 


\section{INTRODUCTION}

Speech and language delay is a common neurological developmental disorder with a prevalence of $2 \%-11 \%$ in preschool children and $9 \%-17 \%$ in children aged approximately 2 years $[1,2]$. Speech refers to the verbal production of language, whereas language refers to the conceptual processing of communication, including both receptive or understanding and expressive languages [3]. Speech and language delay is the slower rate of speech and language development, whereas speech and language disorder is the qualitatively atypical speech and language ability [3]. Speech and language delay is a situation when meaningful speech is not achieved at the age of 2 years [4]. When such speech and language disorders are not treated properly and continued until school age, a behavior or learning disorder may arise [1]. Therefore, early detection and treatment of speech and language disorders is important.

The causes of speech and language disorders include mental retardation, hearing disorders, autism, developmental language disorders, articulation disorders with or without structural abnormality, affective and emotional disorders, lack of education, and the environment $[1,4]$. The most common cause of speech and language delay is mental retardation, and language developmental delay is an initial symptom of mental retardation [4]. A recently emerging cause of speech and language delay includes language environment such as nurturance condition and parental education. Media exposure through televisions, tablets, computers, and smartphones has increased, which may affect the speech and language development of children [5]. In addition, sociodemographic factors may affect the speech and language development of children. Gyeongsangnam-do was the fourth highest province of South Korea, which has international marriage migrants who were not from South Korean from 2007 to 2015, according to the National Statistical Office [6]. When the population is considered, Gyeongsangnam-do would have a considerably high distribution of women who do not speak Korean as their native language, potentially affecting the speech and language development of their children.

Several studies have analyzed the language ability of children with multicultural families. A study using a questionnaire found that $34 \%$ of children with multi- cultural families were at a high risk of language developmental delay [7]. To examine expressive language, 26 children with multicultural families were compared with 105 normally developing children and showed significantly lower expressive vocabulary ability, which was related to their mothers' expressive vocabulary ability [8]. Another study on children with multicultural families in Seoul and Gyeonggi areas found that using the Preschool Receptive-Expressive Language Scale (PRES) and Sequenced Language Scale for Infants (SELSI), 20\% and $70 \%$ of the participants, respectively, were diagnosed with language delay, which was related to the mothers' age, Korean language proficiency, and the duration of residence in Korea [9]. Yoo et al. [10] found that children with multicultural families had significantly lower articulation accuracy. Furthermore, they demonstrated that the error patterns of the children were related to their mothers' native language. Possible causes of language disorders in children with multicultural families are the lack of language stimulation and socioeconomic status [11].

Although studies analyzing the language abilities of children with multicultural families exist, no study directly compared the results of language assessments of children with multicultural families with those of children with Korean parents. Therefore, this study retrospectively analyzes the characteristics of preschool children with speech and language disorders who underwent language assessments to determine their clinical features, and the results of clinical assessments were compared on the basis of purposes of hospital visits and causes of language developmental delay. In addition, the results of the assessments were compared based on the maternal language.

\section{MATERIALS AND METHODS}

\section{Subjects}

Children with language or speech problems who underwent language assessment for the first time between December 2009 and July 2019 were retrospectively reviewed. Those who had a medical history of causative disorders such as cerebral palsy or chromosomal defects before the language assessments were excluded from the study [2]. The following data were collected and recorded when available: age, gender, residence, parental nationality, language environmental characteristics such as parental 
problems (media exposure more than 2 hours per day or indifference) or nurture by grandparents, parents' and siblings' history of language problems, gestational age, other developmental problems, the results of language assessments, intelligence assessments, social maturity scale (SMS), Korean-Wechsler Preschool and Primary Scale of Intelligence, Korean-Childhood Autism Rating Scale (K-CARS), and otorhinolaryngological records, including hearing test results.

\section{Language assessments}

The SELSI or PRES was used to assess the language ability of the children according to the preference of one speech therapist. The SELSI was used when the children were under 2 years old or when the PRES was not applicable. The SELSI is based on the report from the main nurturer and composed of four sections, namely, recognition, concept and semantics, articulation and prosody, and syntax and pragmatics [12]. The PRES was used for children over 2 years old. The PRES divides language into receptive and expressive domains, and each domain assesses the semantics, syntax, and pragmatics of language [13]. In the language assessments, abnormalities were defined as developmental scores of two standard deviations (SDs) away from the mean score of normally developed children or language age delay at least 1 year compared with the standard $[12,13]$. Specific language impairment (SLI) was defined as those with a language quotient of

Table 1. The number and average age of children in each assessment

\begin{tabular}{lcc}
\hline & $\begin{array}{c}\text { Number of } \\
\text { children }\end{array}$ & $\begin{array}{c}\text { Average } \\
\text { age (mo) }\end{array}$ \\
\hline Total number of children & $1,102(100)$ & $41.64 \pm 11.95$ \\
Sex & & \\
$\quad$ Male & $832(75.50)$ & $41.83 \pm 12.34$ \\
$\quad$ Female & $270(24.50)$ & $43.37 \pm 13.38$ \\
$\begin{array}{l}\text { Visual motor integration } \\
\text { Social maturity scale }\end{array}$ & $391(35.48)$ & $43.87 \pm 12.59$ \\
$\begin{array}{l}\text { Korean-Wechsler Preschool } \\
\text { and Primary Scale of }\end{array}$ & $78(43.19)$ & $39.09 \pm 11.93$ \\
$\begin{array}{l}\text { Intelligence } \\
\text { Korean Childhood Autism } \\
\text { Rating Scale }\end{array}$ & $305(27.68)$ & $40.61 \pm 12.13$ \\
\hline Hearing test & $253(22.96)$ & $41.92 \pm 14.96$ \\
\hline
\end{tabular}

Values are presented as number of children (\%) or mean \pm standard deviation. more than 2 SD below the average for age with an intelligence quotient (IQ) of above 85 [2]. Expressive language disorder was defined when the expressive language quotient was more than 2 SD below the average for age with a receptive language quotient of less than 1 SD within the average for age [2].

\section{Statistical analysis}

The data were analyzed using Statistical Package for Social Sciences (version 20.0; IBM Corp., Armonk, NY, USA), and the level of significance was set at $\mathrm{p}<0.05$. Comparisons based on purposes of hospital visits and causes of language developmental delay were conducted using the Kruskal-Wallis test.

\section{RESULTS}

One thousand one hundred and two children with language or speech problems underwent language assessments. Of them, 832 (75.5\%) were male and 270 (24.5\%) were female (Table 1). The mean age was $41.83 \pm 12.34$ months for male children and $43.37 \pm 13.38$ months for female children, and no significant differences in age were found between male and female children (data not shown). From the results of the SELSI or PRES, 1,050 chil-

Table 2. Clinical characteristics of the subjects

\begin{tabular}{|cc|}
\hline \multicolumn{1}{|c}{ Characteristic } & $\begin{array}{c}\text { Number of } \\
\text { subjects }\end{array}$ \\
\hline Language of father & $1,047(99.71)$ \\
\hline Korean & $3(0.29)$ \\
\hline $\begin{array}{l}\text { Others } \\
\text { Language of mother }\end{array}$ & $1,007(95.90)$ \\
\hline Korean & $43(4.10)$ \\
\hline Others & $703(66.95)$ \\
\hline Language environmental problems & $251(23.90)$ \\
\hline None & $96(9.15)$ \\
\hline Parental problems & $870(82.86)$ \\
\hline Nurture by grandparents & $180(17.14)$ \\
\hline Family history & \\
\hline Absent & $937(89.24)$ \\
\hline Present & $113(10.76)$ \\
\hline Other developmental delay & \\
\hline None & \\
\hline Present &
\end{tabular}

Values are presented as number (\%). 
dren (95.3\%) showed language delays. The numbers and average age of children in each assessment are shown in Table 1.

Among the parents of the 1,050 children who showed abnormal results in the SELSI or PRES, 99\% of the fathers used Korean as their native language, whereas $96 \%$ of the mothers used Korean as their native language (Table 2). Twenty-four percent of the children had parental problems such as media exposure more than 2 hours or indifference, and $9 \%$ were nurtured by their grandparents. Furthermore, $17 \%$ of the children had a family history of language or speech disorders. Ten percent of the children had other developmental delays, which were cerebral palsy (most common), Down's syndrome, Lennox-Gastaut syndrome, Kabuki syndrome, hereditary spastic paraplegia, DiGeorge syndrome, West syndrome, congenital myasthenic syndrome, Rabson-Mendenhall syndrome, Smith-Lemli-Opitz syndrome, partial trisomy $9 \mathrm{p}$ syndrome, and neurofibromatosis.
The most common purpose of hospital visits of 792 (71.9\%) children was referring after the national health screening program for infants and children (Table 3). Requesting developmental rehabilitation services and parents' preference to assess the current state of the children were the second and third most common purposes of hospital visits. No statistical differences in the average degree of language delay regarding purposes of hospital visits were found $(\mathrm{p}=0.588$ ).

Among the 1,050 children who had language development delays, 215 (20.5\%) were diagnosed with mental retardation (Table 4). One hundred eighteen children (11.2\%) had SLI, and 110 (10.5\%) children had mixed receptive-expressive language disorder, while the remaining children had expressive language disorder. Fifty-four children $(5.14 \%)$ had autism spectrum disorder (Table 4). The average degree of language delay was greatest in children with autism spectrum disorder and least in children with mixed receptive-expressive language disorder.

Table 3. Purposes of hospital visits and the average age of language delay

\begin{tabular}{lccc}
\hline & $\begin{array}{c}\text { Number of } \\
\text { children }\end{array}$ & $\begin{array}{c}\text { Average language } \\
\text { delay (mo) }\end{array}$ & p-value ${ }^{\text {a) }}$ \\
\hline $\begin{array}{l}\text { Purposes of hospital visits } \\
\begin{array}{l}\text { Referred after the national health screening program for infants } \\
\text { and children }\end{array}\end{array}$ & $792(71.9)$ & $24.12 \pm 17.04$ \\
\hline $\begin{array}{l}\text { Requesting developmental rehabilitation services } \\
\text { Wanted by parents (to assess the current state) }\end{array}$ & $149(13.5)$ & $24.69 \pm 16.71$ \\
\hline $\begin{array}{l}\text { Referred after the national health screening program for infants } \\
\text { and children and requesting developmental rehabilitation ser- } \\
\text { vices }\end{array}$ & $61(6.1)$ & $22.97 \pm 15.80$ \\
\hline \begin{tabular}{l} 
Others \\
\hline
\end{tabular} & $33(3.0)$ & $22.15 \pm 13.88$ \\
\end{tabular}

Values are presented as number of children (\%) or mean \pm standard deviation.

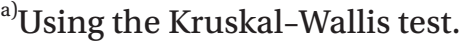

Table 4. Causes of language developmental delay and average age of language delay

\begin{tabular}{|c|c|c|c|}
\hline & Number of children & Average age of language delay (mo) & p-value ${ }^{a}$ \\
\hline Causes of language developmental delay & & & $0.000^{*}$ \\
\hline Mental retardation & $215(20.5)$ & $23.69 \pm 8.94$ & \\
\hline Specific language impairment & $118(11.2)$ & & \\
\hline Mixed receptive-expressive language disorder & $110(10.5)$ & $18.18 \pm 9.11$ & \\
\hline Expressive language disorder & $8(0.76)$ & $24.37 \pm 7.93$ & \\
\hline Autism spectrum disorder & $54(5.14)$ & $31.12 \pm 13.25$ & \\
\hline
\end{tabular}

Values are presented as number of children (\%) or mean \pm standard deviation.

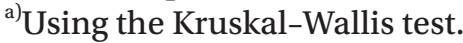

${ }^{*} \mathrm{p}<0.05$. 
Among the 1,050 children who had language development delay, 1,007 were with mothers using Korean as their native language, while 43 had mothers who did not use Korean as their native language (Table 5). The average age of language delay was $23.69 \pm 15.78$ months in the former group, while it was $26.82 \pm 13.89$ months in the latter group. One hundred nine children with mothers using Korean as their native language had SLI, and nine children with mothers not using Korean as their native language had SLI. In the former group, 57\% showed IQs lower than 70 , whereas in the latter group, $64 \%$ showed IQs lower than 70 . Furthermore, 37\% of the children in the former group showed SMS lower than 70, whereas $65 \%$ of the children in the latter group showed social quotient (SQ) lower than 70 . In addition, $67 \%$ of the children in the former group showed full-scale intelligence quotients (FSIQs) lower than 70, whereas in the latter group,

Table 5. Comparison by the maternal language

\begin{tabular}{lcc}
\hline & \multicolumn{2}{c}{ Maternal language } \\
\cline { 2 - 3 } & Korean & Not Korean \\
\hline Number of children & $1,007(95.9)$ & $43(4.1)$ \\
Age (mo) & $45.34 \pm 19.62$ & $47.63 \pm 16.48$ \\
Average language delay (mo) & $23.69 \pm 15.78$ & $26.82 \pm 13.89$ \\
SLI & 109 & 9 \\
VMI & 358 & 33 \\
IQ $<70$ & $205(57.3)$ & $21(63.6)$ \\
SMS & 439 & 37 \\
SQ $<70$ & $164(37.4)$ & $24(64.9)$ \\
K-WPPSI & 70 & 8 \\
FSIQ $<70$ & $46(65.7)$ & $5(62.5)$ \\
\hline PIQ $<70$ & $32(45.7)$ & $4(50.0)$ \\
VIQ $<70$ & $42(60.0)$ & $5(62.5)$ \\
K-CARS & 285 & 20 \\
\hline K-CARS $>28$ & $50(17.5)$ & $4(20.0)$ \\
Hearing test & 227 & 26 \\
Hearing abnormality & $10(4.4)$ & $0(0)$ \\
\hline Values
\end{tabular}

Values are presented as number (\%) or mean \pm standard deviation.

SLI, specific language impairment; VMI, visual motor integration; IQ, intelligence quotient; SMS, social maturity scale; SQ, social quotient; K-WPPSI, Korean-Wechsler Preschool and Primary Scale of Intelligence; FSIQ, fullscale intelligence quotient; PIQ, performance intelligence quotient; VIQ, verbal intelligence quotient; KCARS, Korean-Childhood Autism Rating Scale.
$63 \%$ showed FSIQs lower than 70 . Forty-six percent and $50 \%$ in the former and latter groups, respectively, showed performance IQs lower than 70 , and $60 \%$ and $63 \%$ in the former and latter groups, respectively, showed verbal IQs lower than 70. Eighteen percent of children with mothers using Korean as their native language and $20 \%$ of children with mothers not using Korean as their native language showed K-CARS scores of more than 28. Hearing test abnormalities were observed in $4 \%$ of the children with mothers using Korean as their native language, and no children with mothers not using Korean as their native language had hearing test abnormalities.

\section{DISCUSSION}

This retrospective study showed that $95 \%$ of the children with language or speech problems had language delay in the SELSI or PRES. Therefore, all children with such a chief complaint should undergo intensive language assessments.

In this study, male children were three times higher in number than female children. This is similar to a study that showed that a 3-4 times higher number of male children had global developmental delay, developmental language disorders, and autism spectrum disorders [14].

Thirty-three percent of the children had language environmental problems that may have caused the abnormalities in the language assessments (Table 2). This result was supported by a previous study showing the decrement in the Communicative Development Inventory using video viewing [15]. Cho et al. [5] have analyzed the risk of early media exposure before 24 months and showed that children who were exposed to electronic media early had 13.5 times higher risk of language development delay than controls. In their study, the type of media exposure did not significantly affect the language delay but the exposure time per day did. Therefore, exposing children under 2 years old to electronic media has been discouraged by the American Academy of Pediatrics since 2011 [16]. However, some studies reported that no clear negative relationship was found between media exposure and development [17]. Furthermore, a recent report suggested that media exposure could positively affect language development when the media are educational [18]. Although there has been controversy, media exposure time at an early age without supervision may 
deprive children the chance for more reciprocal stimulus that can help normal development. Therefore, media exposure to children would be considered with more caution. Furthermore, indifference of parental problems may be explained by a previous study reporting that parents with a more concerned behavior may read and tell stories and encourage more often their children to talk or listen, which works as a proper stimulus for language development [19]. However, our study did not categorize parental problems in more detail, and media exposure time was not investigated. Therefore, further investigations with categorized parental problems and additional information about media exposure type and time might be required.

In addition, nurture by grandparents seemed to increase the probability of abnormalities in language assessments. Studies dealing with the role of caregiver exist; however, no study has analyzed the direct relationship between nurture by grandparents and language development. One study has reported that grandparents separated from children lowered the children's vocabulary scores [20]. However, that study did not focus on grandparents as the main caregiver. A British study compared group care in nurseries with individual care from caregivers, such as grandparents and showed that group care in nurseries was related to higher cognitive scores than individual care from caregivers, such as grandparents and nannies [21]. Their results are different from those of our study since the comparison in this study was between nurture by grandparents and nurture by parents. Since the economic activity of women has been increased, the main caregiver has been more diversified. Thus, further study on the role of the main caregivers, including grandparents, would be necessary.

Seventeen percent of the children in this study showed a family history of speech and language problems. In addition, a recent study involving 228 children showed that in addition to the low income, nonattendance in preschool education, low maternal education, the presence of siblings, and birth order were significant risk factors for speech and language delay and disorders [22]. The results in this study are similar to those of a previous study that showed that $20 \%-40 \%$ of children with SLI had a family history of speech and language delay and disorders, which was higher than that (4\%) in the general population [23]. The difference in prevalence might be due to the difference in the definition of positive family history. For example, our study broadly collected this information based on the caregivers' report on family history when any known parents and siblings had speech and language delay or difficulty even when it was temporary.

The most common cause of language developmental delay was mental retardation in this study, followed by SLI and autism spectrum disorders, which is similar to the results of a study, which analyzed 128 children with suspected language delay [24]. The worldwide population prevalence of autism is approximately $1 \%$ [25], but $5 \%$ of the children in this study showed K-CARS scores of more than 28, the cutoff point. Therefore, children with language and speech disorders should undergo assessments to evaluate the possibility of having autism. Clearly diagnosing children with language developmental delay is important since the approach and result of speech therapy differs according to their diagnoses [26]. However, clarifying the diagnosis might be difficult because developmental disorders such as mental retardation and autism spectrum disorders are on one continuum without distinct classification [24]. Therefore, the categorization of the results of each developmental and language assessment tests might be necessary. Furthermore, this study showed that children with autism spectrum disorder had the greatest language delay among its causes, such as mental retardation and SLI. This might be helpful when examining children with language delay since children with greater language delay would have more probability of having autism spectrum disorder.

Greater language delay in children with mothers not using Korean as their native language is consistent with previous studies [7-11]. However, no study has elucidated the relationship between maternal language and SQ as this study. The result may indirectly explain the role of language development in sociality or the role of sociality in language development. Children with multicultural families may have low social maturity skills because of language delay and vice versa. Therefore, further studies that analyze the relationship between sociality and language in a multicultural family might be necessary.

This study has some limitations. First, we did not subdivide maternal native language and their levels of language ability in Korean. Since different maternal native languages affect children differently, further study with subdivision might be helpful. Second, this study enrolled 
a relatively small number of children with mothers not using Korean as their native language, which may limit the generalization of the results and statistical analysis. Lastly, this study only enrolled children from the Gyeongsangnam-do area; therefore, a similar study involving the whole country would be helpful in generalizing and popularizing the result.

In conclusion, this study showed that language environments such as media exposure more than 2 hours per day, parental indifference, and nurture by grandparents are essential factors that may cause speech and language disorders. In addition, children with mothers not using Korean as their native language showed more language delay and lower SQs. Therefore, comprehensive assessments and focus on the language environment might be required to help the diagnosis and treatment of children with speech and language disorders, and children with multicultural families require more attention.

\section{CONFLICT OF INTEREST}

No potential conflict of interest relevant to this article was reported.

\section{AUTHOR CONTRIBUTION}

Conceptualization: Shin H, Lee ES. Methodology: Yoon $\mathrm{CH}$, Oh MK. Formal analysis: Lee ES. Kim HS, Min HS. Visualization: Chun SW, Lim SK. Writing-original draft: Byun H, Lee ES. Writing-review and editing: Kim HS, Byun H, Lee ES. Approval of final manuscript: all authors.

\section{REFERENCES}

1. Kim SJ, Kim YH, Lee YK, Kim DU, Han SH, Chung SY, et al. The clinical features of children with developmental language disorder. J Korean Child Neurol Soc 2001;9:122-8.

2. Choi JY, Kim CA, Song IJ, Lee KW, Gang MJ, Jung MJ, et al. Clinical review of children diagnosed as specific language impairment. J Korean Child Neurol Soc 2011;19:8-17.

3. McLaughlin MR. Speech and language delay in children. Am Fam Physician 2011;83:1183-8.

4. Kim GN, Lee KS, Kim JY. Speech delay of children with mental retardation. J Korean Child Neurol Soc
2009;17:50-7.

5. Cho MS, Choi S, Kim KM, Yi YY, Kim SS. Effect of media exposure to language development. J Korean Child Neurol Soc 2017;25:34-8.

6. Korean Statistical Information Service. Survey of foreign residents in Korea [Internet]. Daejeon, Korea: Statistics Korea; 2016 [cited 2019 Dec 28]. Available from: http://kosis.kr/statHtml/statHtml. do?orgId=110\&tblId=TX_11025_A010\&conn_path=I2.

7. Pae SY, Kwak KJ, Kim KY, Jung KH, Kim HJ. Supporting the language development of children from multicultural families: a survey of mothers and developmental supporters. J Speech Hear Disord 2009;18:165-84.

8. Lee SJ, Shin JC, Kim HH, Kim HS. A study on expressive vocabulary ability in multicultural family children: based on K-BNT-C. J Speech Lang Hear Disord 2008;17:95-115.

9. Oh SJ, Kim YT, Kim YR. Preliminary study on language characteristics and related family factors in children from multicultural family. Spec Educ Res 2009;8:13761.

10. Yoo HJ, Kim HH, Kim WS, Shin JC. Articulation ability and phonological process in multicultural family children. Speech Sci 2008;15:133-44.

11. Chang YK, Lee KY, Kwak KJ, Sung HR. Relations of maternal linguistic inputs to lexical development of Korean infants. Korean J Develop Psychol 2003;16:22741.

12. Kim YT. Content and reliability analyses of the Sequenced Language Scale for Infants (SELSI). Commun Sci Disord 2002;7:1-23.

13. Kim YT, Sung TJ, Lee YK. Preschool receptive-expressive language scale (PRES). Seoul, Korea: Seoul Community Rehabilitation Center; 2003.

14. Shevell MI, Majnemer A, Rosenbaum P, Abrahamowicz M. Etiologic determination of childhood developmental delay. Brain Dev 2001;23:228-35.

15.Zimmerman FJ, Christakis DA, Meltzoff AN. Associations between media viewing and language development in children under age 2 years. J Pediatr 2007;151:364-8.

16. Council on Communications and Media. Media use by children younger than 2 years. Pediatrics 2011;128:1040-5.

17. Foster EM, Watkins S. The value of reanalysis: TV viewing and attention problems. Child Dev 
2010;81:368-75.

18. Ferguson CJ, Donnellan MB. Is the association between children's baby video viewing and poor language development robust? A reanalysis of Zimmerman, Christakis, and Meltzoff (2007). Dev Psychol 2014;50:129-37.

19. Hammer CS, Tomblin JB, Zhang X, Weiss AL. Relationship between parenting behaviours and specific language impairment in children. Int J Lang Commun Disord 2001;36:185-205.

20. Reynolds SA, Fernald LCH, Deardorff J, Behrman JR. Family structure and child development in Chile: A longitudinal analysis of household transitions involving fathers and grandparents. Demogr Res 2018;38:1777-814.

21. Sylva K, Stein A, Leach P, Barnes J, Malmberg LE; FCCC-team. Effects of early child-care on cognition, language, and task-related behaviours at 18 months: an English study. Br J Dev Psychol 2011;29(Pt 1):18-45.
22. Uzun Cicek A, Akdag E, Celebi Erdivanli O. Sociodemographic characteristics associated with speech and language delay and disorders. J Nerv Ment Dis 2020;208:143-6.

23. Choudhury N, Benasich AA. A family aggregation study: the influence of family history and other risk factors on language development. J Speech Lang Hear Res 2003;46:261-72.

24. Kim SW, Shin JB, You S, Yang EJ, Lee SK, Chung HJ, et al. Diagnosis and clinical features of children with language delay. J Korean Acad Rehabil Med 2005;29:58490.

25. Lai MC, Lombardo MV, Baron-Cohen S. Autism. Lancet 2014;383:896-910.

26. Kim SW, Shin JB, Bae MS, Chung HJ, Kim YK, Song $\mathrm{JH}$. Effects of speech therapy in children with specific language impairment and mild intellectual disability. J Korean Acad Rehabil Med 2011;35:48-54. 